\title{
A COMPONENT-BASED APPROACH TO MODELLING BEAM BOTTOM FLANGE BUCKLING AT ELEVATED TEMPERATURES
}

\author{
Guan Quan, Shan-Shan Huang, Ian Burgess \\ University of Sheffield, Department of Civil and Structural Engineering, Sheffield, UK
}

\begin{abstract}
In this study, an analytical model of the combination of beam-web shear buckling and bottomflange buckling at elevated temperatures has been created. This analytical model is able to track the force-deflection path in the post-buckling stage. A range of 3D finite element models has been created using the ABAQUS software. Comparisons have been carried out between the proposed analytical model, finite element modelling and the existing Dharma's theoretical model. Comparisons indicate that the proposed method is able to provide with accurate predictions for Class 1 and Class 2 beams, and performs better than the existing model, especially for slender beams. A component-based model has been created based on the analytical model, and in due course to be implemented into the software Vulcan for global structural fire analysis.
\end{abstract}

Keywords: shear buckling, bottom-flange buckling, component-based model, fire

\section{INTRODUCTION}

The structural behaviour in real frames observed in the full-scale Cardington Fire Tests (Kirby, 1998, Huang et al., 1999) was very different from that observed from furnace tests on isolated elements. Consequently, the awareness of the importance of performance-based design, which sufficiently considers the interactions between different members in the structure, increased. However, full-scale fire tests are expensive. To carry out finite-element modelling of an entire structure, including the joints, is computationally demanding. Component-based method is a practical alternative approach to model the joints and their adjacent zones; the component-based models will be embodied into global structural analysis in due course.

The Cardington fire tests in 1995-96 (Newman et al., 2000) indicated that beam-web shear buckling as well as beam bottom flange buckling, near to the ends of steel beams, is very prevalent under fire conditions, as shown in .

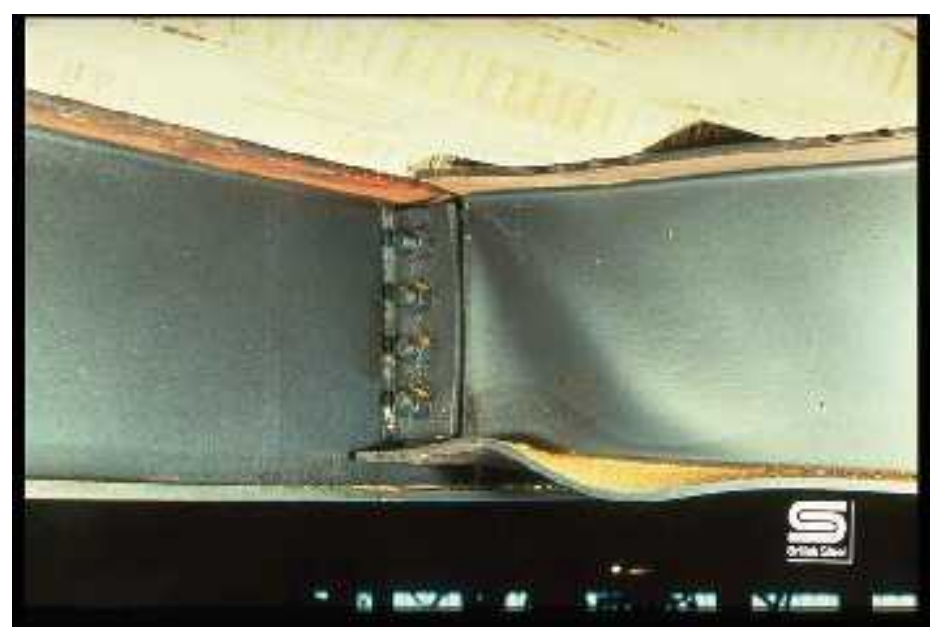

Fig. 1 Shear buckling and bottom-flange buckling in Cardington fire test (Newman et al., 2000)

These phenomena can have significant effects on the beam deflection as well as force distribution within the adjacent joint. The research by Elghazouli et al.(Elghazouli and Izzuddin, 1999) addressed the influence of local buckling on frame response although local buckling may have 
insignificant configurations for isolated members on fire rating. However, the local buckling model presented in Elghazouli's work is based on elastic plate buckling theory (Timoshenko and Gere, 1961), which is not appropriate for representing the buckling behaviour of Class 1 and 2 sections. In this study, an analytical model of the combination of beam-web shear buckling and bottom-flange buckling at elevated temperatures has been created based on Dharma's model (Dharma, 2007). This model is capable of predicting the local buckling behaviour in the post-buckling stage. Together with the assumption that the characteristics of the buckling zone are identical to those of the normal beam in the pre-buckling stage, this analytical model is able to track the complete force-deflection path of the beam from its initial loading to post-buckling. A range of 3D finite element models has been created using the ABAQUS software. Comparisons have been carried out between the proposed analytical model, finite element modelling and Dharma's model, which indicate that the proposed method gives better predictions compared with Dharma model. A component-based model has been created based on the analytical model, and to be further implemented into the software Vulcan for global structural fire analysis.

\section{DEVELOPMENT OF ANALYTICAL MODEL}

The development of the analytical model is explained using a short cantilever I-beam section as an example. By applying different combinations of bending moment and shear force at its end, this model can represent the bucking panel of a beam of any length, loading and boundary conditions. When the bottom-flange buckling wavelength calculated from Eq. (1) (Dharma, 2007) is shorter than the beam depth, the length of the buckling zone is identical to the $L_{p}$ calculated from this equation. Otherwise, the length of the buckling zone is capped to the beam depth.

$L_{p}=0.713 \sqrt{\frac{275}{f_{y}}}\left(\frac{d}{b}\right)^{1 / 4}\left(\frac{t_{f}}{t_{w}}\right)^{3 / 4}\left(\frac{k_{E} / k_{y}}{0.7}\right)$

If the material properties, as shown in Fig. 2, for steel at temperatures higher than $400^{\circ} \mathrm{C}$ are used, the vertical force-deflection relationship of the buckling panel can be illustrated as Fig. 3. The proposed analytical model divides the loading procedure into three stages: pre-buckling, plateau and post-buckling stages.

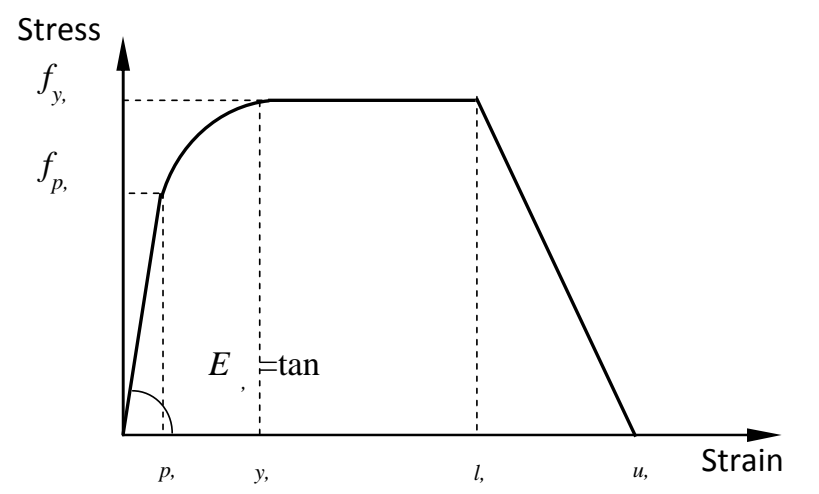

Fig. 2 Stress-strain relationship of structural steel

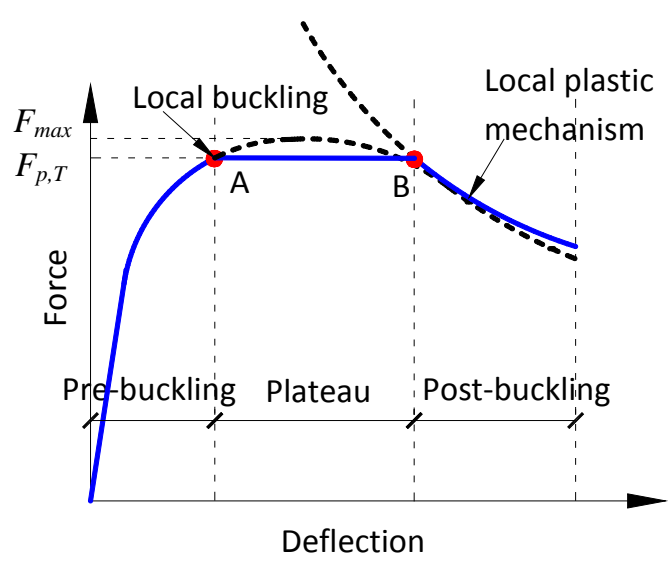

Fig. 3 Schematic force-deflection curve of a buckling panel

In the pre-buckling stage, the calculation rules follow that for beams at elevated temperatures. The plateau $\mathrm{AB}$ occurs at the reaction force when the sectional plastic moment capacity is reached at the middle of the buckling zone. The Point B is the point at which bottom-flange buckling occurs. In the post-buckling stage, it is assumed that the collapse mechanism is composed of yield lines and plastic yield zones. The plastic buckling mechanism is shown in Fig. 4. The calculation principle is based on the equality of the internal plastic work and the external loss of potential energy of the load. The internal plastic work $W_{\text {int }}$ includes the work done by the flanges, which is composed of 
$\sum_{i}\left(W_{l}\right)_{i}$ due to rotation about yield lines and $\sum_{j}\left(W_{z}\right)_{j}$ due to axial deformation of the plastic zones, as well as the work $W_{W}$ done by the beam web due to its deformation during shearing buckling. The total internal work can be expressed as Eq. (2).

$W_{\mathrm{int}}=\frac{1}{4} \sum_{i}\left(l_{p} t^{2} f_{y} \theta_{1}\right)_{i}+\sum_{j}\left(A_{p} t f_{y} \varepsilon\right)_{j}+W_{W}$

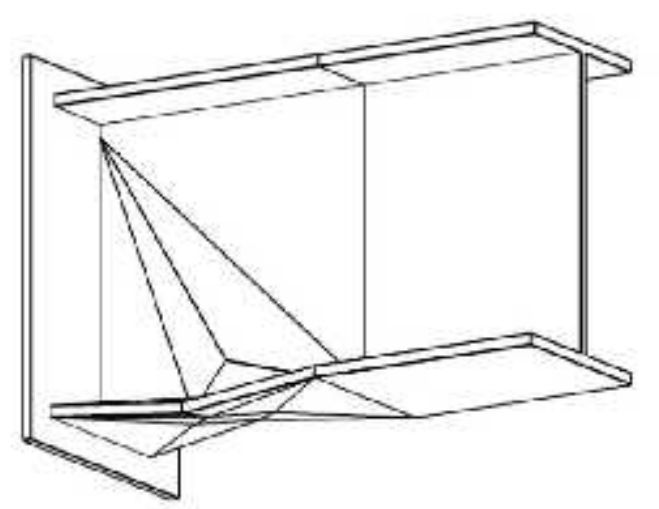

Fig. 4 Plastic Buckling Mechanism

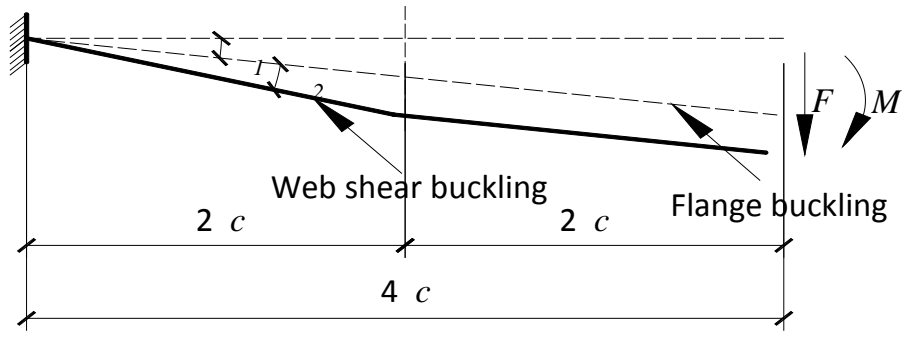

Fig. 5 The effects of flange buckling and beam-web shear buckling on beam vertical deflection

The total deflection of the buckling zone is composed of the deflection caused by both bottomflange buckling and beam-web shear buckling, as shown in Fig. 5. The influence of bottom-flange buckling is to cause a rotation of the whole beam-end about the top corner of the beam while the effect of shear buckling is a parallel movement of the opposite edges of the shear panel. When applying a shear force and a bending moment at the end of the buckling zone, the total external work can be expressed by Eq. (3).

$$
W_{e x t}=\sum P_{i} \Delta_{i}=F(4 \beta c) \theta_{1}+F(2 \beta c) \theta_{2}+M\left((4 \beta c) \theta_{1}+(2 \beta c) \theta_{2}\right) /(4 \beta c)
$$

\section{VALIDATION AGAINST FINITE ELEMENT MODELLING}

\subsection{Development of the ABAQUS models}

The commercial finite element software ABAQUS was used to simulate the buckling phenomena in the vicinity of beam-column connections at $615^{\circ} \mathrm{C}$. The four-noded shell element S4R (Hibbit et al., 2005), which is capable of simulating buckling behaviour was adopted. A $15 \mathrm{~mm} \times 15 \mathrm{~mm}$ element size was used according to mesh sensitivity analysis. The Riks approach was used in order to identify the descending curve in the post-buckling stage. Cantilever models with different combination of shear force and bending moment were set up. The image of the ABAQUS model is shown in Fig. 6 (a). All the cantilevers sheared the same configurations except for the beam-web thickness. The beam-web thicknesses varied from $5 \mathrm{~mm}$, which is the extreme case for Class 2 beams, to $8 \mathrm{~mm}$. The cross-section dimensions are shown in Fig. 6 (b). For each beam configuration, three moment-shear force ratio $(M / F) 500,1000$ and 1500 were applied. The length identical to twice the beam depth was set up intending to avoid the influence of the boundary conditions on the ABAQUS model, and to minimize the influence of the elastic deflection due to bending. The stressstrain relationship of the beam material at $615^{\circ} \mathrm{C}$ was defined according to Eurocode 3 (CEN, 2005). The details of the material properties used in the ABAQUS models are shown in Table 1.

Table 1 Material Properties

\begin{tabular}{|c|c|c|c|c|}
\hline$f_{y, \theta}\left(\mathrm{N} / \mathrm{mm}^{2}\right)$ & $\varepsilon_{y, \theta}(\%)$ & $\varepsilon_{t, \theta}(\%)$ & $\varepsilon_{u, \theta} \quad(\%)$ & $E_{a, \theta} \quad\left(\mathrm{N} / \mathrm{mm}^{2}\right)$ \\
\hline 267.96 & 2 & 15 & 20 & $1.411 \times \mathrm{e}^{5}$ \\
\hline
\end{tabular}




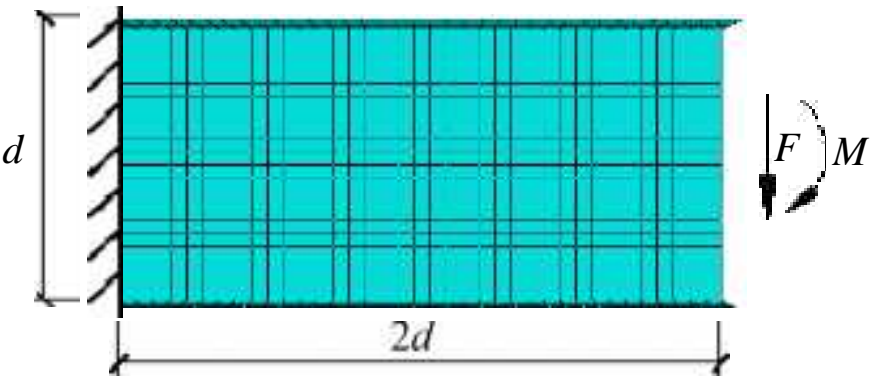

(a)

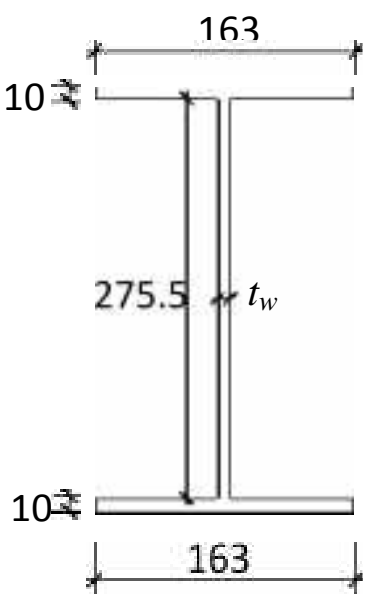

(b)

Fig. 6 Finite element model: (a) image of finite element model; (b) cross-section dimension

\subsection{Comparison between the analytical model, Dharma's model and FEA}

The force-displacement relationships given by the proposed analytical model, existing Dharma's model and the ABAQUS analysis have been compared. The detailed curves for two extreme cases with web thickness of $5 \mathrm{~mm}$ and $8 \mathrm{~mm}$, the ratio of bending moment and shear force to be 1000 are shown in Fig. 7. The line with diamond marker, which is denoted "Elastic-plastic", represents the force-deflection relationship when the plastic moment resistance is reached at the middle of the flange buckling zone. The smooth line without markers represents the result of finite element modelling. The lines with square markers and triangular markers are the results from the new proposed buckling model and Dharma's model respectively. It can be seen that the new proposed analytical model gives comparisons to the FE modelling for beams with either $5 \mathrm{~mm}$ or $8 \mathrm{~mm}$ web. However, Dharma's model tends to over-estimate the beam capacity when the beam web is $5 \mathrm{~mm}$.

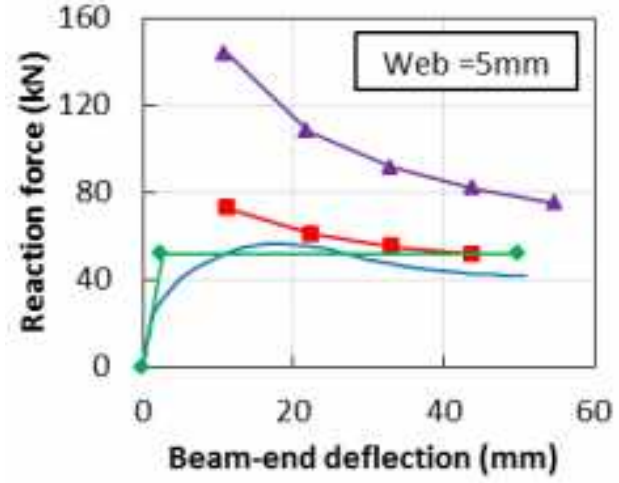

(a)

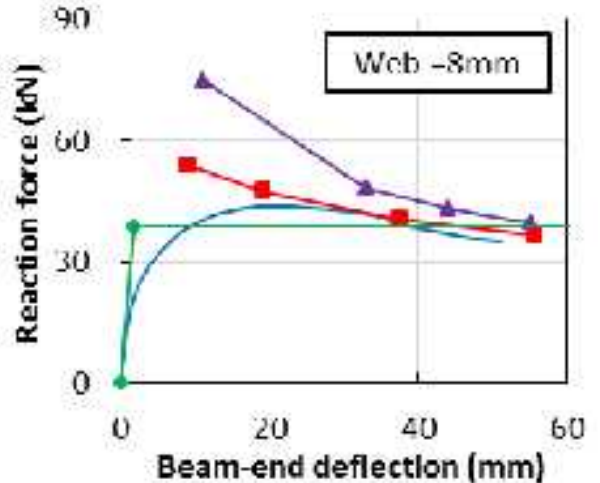

(b)

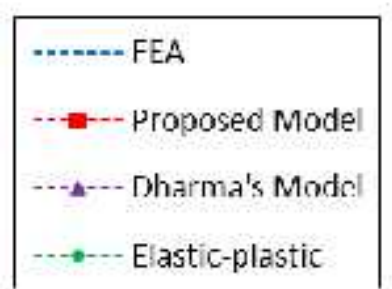

Fig. 7 Comparison between the analytical model, Dharma's model and FE analysis

Fig. 8 shows the comparison of the proposed model and Dharma's model in terms of force-web thickness relationships. The variable $F_{F E A}$ represents the peak load of the FE modelling. $F_{N}$ and $F_{D}$ are the load of the new analytical model and Dharma's model respectively, corresponding to the same deflection with $F_{F E A}$. The vertical axis of is the predicted load of either new model $\left(F_{N}\right)$ or Dharma's model $\left(F_{D}\right)$ normalized with the corresponding FEA peak load $\left(F_{F E A}\right)$. As can be seen from Fig. 8, Dharma's model tends to over-estimate the beam loading capacity when the beam-web thickness is $5 \mathrm{~mm}$ and $6 \mathrm{~mm}$, whereas gives a good prediction when the beam-web thickness is $7 \mathrm{~mm}$ and $8 \mathrm{~mm}$. The new analytical model is able to give a better stable upper-bound, which is always below 1.3 in terms of load capacity, for both slender and stocky beams within the analysed range. This indicates that the new model can give a good prediction for the beam-load-capacity at the postbuckling stage. However, more parametric studies need to be carried out to investigate on the factors or ratios of the beam configurations, which influence accuracy of the results. 


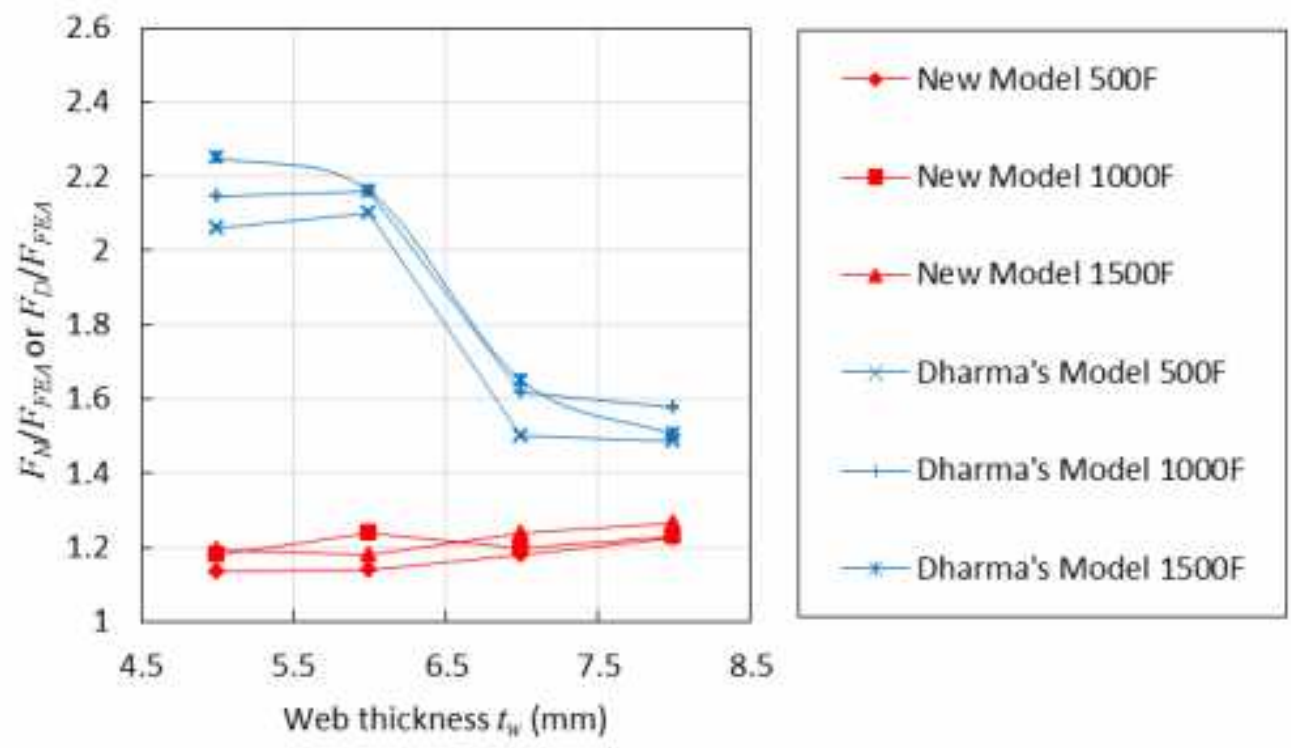

Fig. 8 Comparison between the proposed analytical model and Dharma's model

\section{COMPONENT-BASED MODEL}

One of the major objectives of this research is to develop a new beam-web shear buckling component and a new flange-buckling component based on the component-based method, and implement them to the adjacent joint element, as shown in Fig. 9, to carry out performance-based analysis under fire conditions. The flange-buckling component is a zero-length compressive spring as the effect of the bottom flange buckling is the rotation of the whole cross section. The length of the shear buckling component is non-zero because the effect of shear buckling is transverse drift, which relies on both the shear-panel length and rotational angle. The length of the beam-web shear buckling component has been defined identical to beam depth $(d)$.
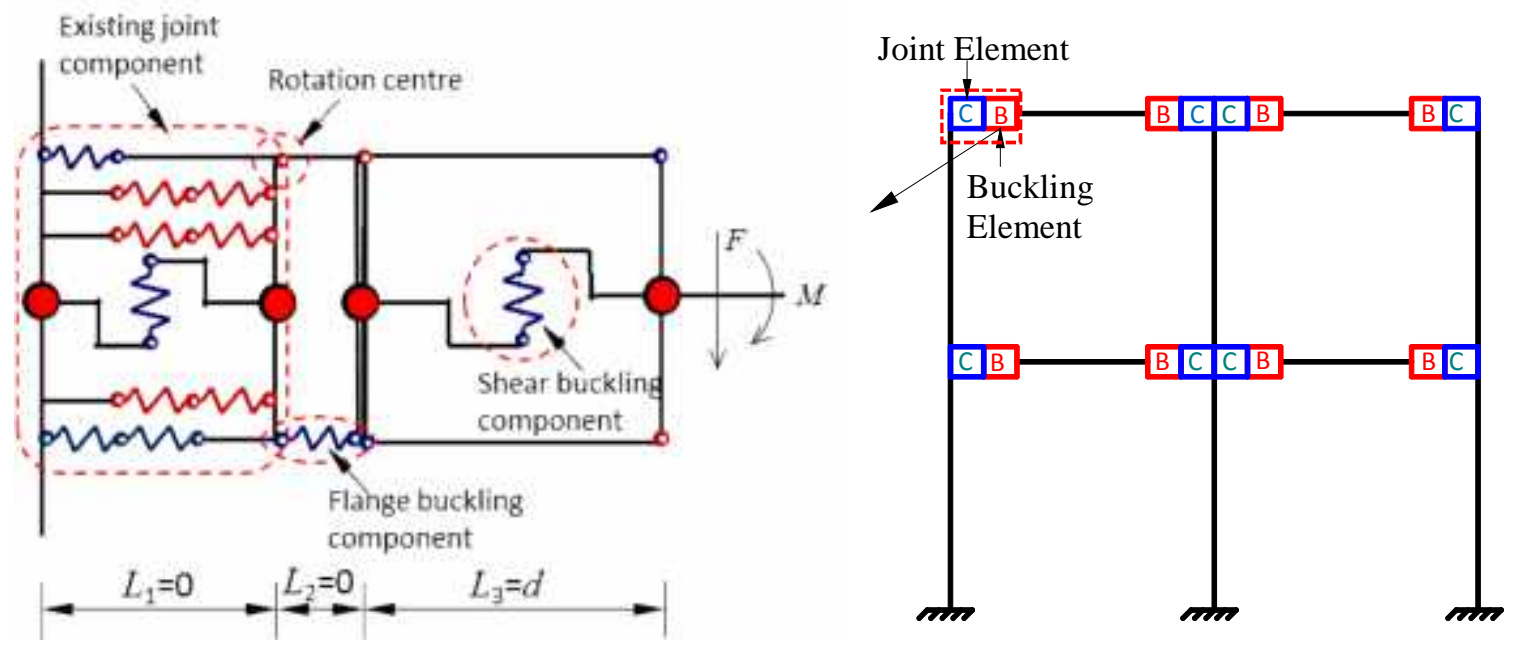

Fig. 9 Component-based model for buckling components

\section{CONCLUSIONS}

- This paper presented a proposed analytical model to predict the post-buckling behaviour of steel beams at elevated temperatures.

- A range of finite element models were created using the finite element software ABAQUS. The proposed analytical model was compared with the existing Dharma's model and the FE models. The comparison shows that the proposed method provides a stable upper bound in terms of reaction force-deflection relationship within Class 1 and Class 2 range according to 
the classification method provided by Eurocode 3 (CEN, 2005), while Dharma's model tends to overestimate beam post-buckling capacity when the beam web is relatively slender.

- The loading resistance of a steel beam at elevated temperatures involves three stages: Nonlinear pre-buckling, Plateau and Post-buckling. A whole force-deflection relationship of a steel beam from the initial loading to post-buckling stage was achieved. Component-based models of the beam-web shear buckling component and the bottom flange buckling component were created. The newly developed beam-web shear buckling component and bottom-flange buckling component based will be implemented to the adjacent joint element to carry out performance-based analysis under fire conditions.

\section{REFERENCES}

CEN 2005. BS EN 1993-1-2. Design of steel structures. Part 1.2: General rules - Structural fire design. UK: British Standards Institution.

Dharma, R. B. 2007. Buckling behaviour of steel and composite beams at elevated temperatures. Ph.D. thesis. Singapore: Sch. of Civ. and Env. Engrg., Nanyang Technological University.

Dlghazouli, A. \& Izzuddin, B. Significance of local buckling for steel frames under fire conditions. 4th International Conference on Steel and Aluminium Structures (ICSAS 99), 1999. Elsevier Science BV, 727-734.

Hibbit, D., Karlsson, B. \& Sorenson, P. 2005. ABAQUS reference manual 6.7. Pawtucket: ABAQUS Inc.

Huang, Z., Burgess, I., Plank, R. \& Reissner, M. 1999. Three-dimensional modelling of two fullscale, fire tests on a composite building. Proceedings of the ICE-Structures and Buildings, 134, 243-255.

Kirby, B. 1998. The behaviour of a multi-storey steel framed building subject to fire attackexperimental data; British Steel Swinden Technology Centre, United Kingdom.

Newman, G. M., Robinson, J. T. \& Bailey, C. G. 2000. Fire safe design: A new approach to multistorey steel-framed buildings, Steel Construction Institute.

Timoshenko, S. P. \& Gere, J. M. 1961. Theory of elastic stability. 1961. McGraw-Hill, New York. 